\title{
NEUROFIBROMATOSE TIPO 1 - IMPACTOS NA INFÂNCIA E ADOLESCÊNCIA
}

\author{
Aline Santana Bortoluzzi ${ }^{1}$ \\ Odirlei Antonio Magnagnagno ${ }^{2}$ \\ Leandra Ferreira Marques Nobre ${ }^{3}$
}

\begin{abstract}
Resumo: A neurofibromatose tipo 1 (NF-1) é uma síndrome enquadrada no grupo das neurofibromatoses, as quais são classificadas como genodermatoses neurocutâneas. É uma das doenças genéticas mais frequentes, acometendo 1 a cada 3000 nascidos vivos. Seu diagnóstico é feito na presença de dois ou mais dos critérios clínicos estabelecidos pelo National Institutes of Health em 1988. A maior parte dos sinais e sintomas aparece na infância, o que faz com que a doença possa ocasionar alterações fisiológicas e de desenvolvimento neste período de vida do doente. Estudos mostram, cada vez mais, que a doença pode comprometer de forma significativa o desenvolvimento neuropsicomotor e social do indivíduo, que também se encontra pré-disposto a desenvolver transtornos do neurodesenvolvimento como autismo, déficit de atenção e hiperatividade. Devido às comorbidades que a síndrome pode desencadear, o acompanhamento periódico multiprofissional e orientação precisa são cruciais para um bom prognóstico e melhora da qualidade de vida destes doentes.
\end{abstract}

Palavras-Chave: neurofibromatose; desenvolvimento; socialização; infância; acompanhamento.

\section{NEUROFIBROMATOSIS TYPE 1 - IMPACTS ON CHILDHOOD AND ADOLESCENCE}

\begin{abstract}
Neurofibromatosis type $1(N F-1)$ is a syndrome within the neurofibromatosis group, which are classified as neurocutaneous genodermatoses. It is one of the most common genetic diseases, affecting 1 in 3,000 live births. Its diagnosis is made in the presence of two or more of the clinical criteria established by the National Institutes of Health in 1988. Most signs and symptoms appear in childhood, which causes the disease to cause physiological and developmental changes in this period of life of the sick. Studies show that the disease can significantly compromise the neuropsychomotor and social development of the individual, who is also predisposed to develop neurodevelopmental disorders such as autism, attention deficit hyperactivity disorder, and hyperactivity. Because of the comorbidities that the syndrome may elicit, periodic multi-professional follow-up and precise guidance are crucial for a good prognosis and improvement of the quality of life of these patients.
\end{abstract}

Key Words: neurofibromatosis; development; socialization; childhood; monitoring.

\section{NEUROFIBROMATOSIS TIPO 1 - IMPACTOS EN LA INFANCIA Y ADOLESCENCIA}

Resumen: La neurofibromatosis tipo 1 (NF-1) es un síndrome enmarcado en el grupo de las neurofibromatosis, que se clasifican como genodermatosis neurocutáneas. Es una de las enfermedades genéticas más frecuentes, afectando a 1 de cada 3000 nacidos vivos. Su diagnóstico se realiza en presencia de dos o más de los criterios clínicos establecidos por el National Institutes of Health en 1988. La mayoría de los signos y síntomas aparecen en la infancia, lo que hace que la enfermedad pueda ocasionar alteraciones fisiológicas y de desarrollo en este período de tiempo Vida del paciente. Los estudios muestran cada vez más que la enfermedad puede comprometer de forma significativa el desarrollo neuropsicomotor y social del individuo, que también se encuentra pre-dispuesto a desarrollar trastornos del neurodesarrollo como autismo, déficit de atención e hiperactividad. Debido a las comorbilidades que el síndrome puede desencadenar, el seguimiento periódico multiprofesional y orientación precisa son cruciales para un buen pronóstico y mejora de la calidad de vida de estos pacientes.

Palabras Clave: neurofibromatosis; Desarrollo; Socialización; La infancia; El seguimiento.

\section{Introdução}

A neurofibromatose, uma doença caracterizada como uma genodermatose neurocutânea, é uma patologia genética com uma prevalência significativa na população mundial, acometendo um a cada 3000 nascidos vivos (AZULAY, 2008). Costuma acometer vários setores do

\footnotetext{
${ }^{1}$ Acadêmica do Curso de Medicina da Faculdade Assis Gurgacz de Cascavel - PR.

2 Mestre em Administração e Negócios pela Pontifícia Universidade Católica do Rio Grande do Sul, (2015). Avaliador de Projetos do Comitê de Ética do Centro Universitário Assis Gurgacz Cascavel - PR.

3 Mestre em Patologia pela Fundação Universidade Federal de Ciências da Saúde de Porto Alegre, (2015). Professora do Ambulatório de Dermatologia da Faculdade Assis Gurgac Cascavel - PR.
} 
organismo, sendo uma síndrome de difícil diagnóstico pelos profissionais médicos. Esta síndrome possui subtipos que apresentam poucas características em comum e muitas peculiaridades individuais que permitem uma nítida distinção entre eles (GELLER \& BONALUMI FILHO, 2001).

Dos subtipos de neurofibromatoses, a neurofibromatose tipo 1 é a mais comum, englobando cerca de $90 \%$ dos casos de neurofibromatose. A neurofibromatose tipo 1 (NF-1) é um dos distúrbios monogênicos mais freqüentes na infância, sendo considerada a mutação autossômica dominante espontânea (denominada mutação de novo) mais comum nos seres humanos (GELLER \& BONALUMI FILHO, 2001). Apresentando critérios clínicos desenvolvidos em 1988 pelo National Institutes of Health, é uma doença que pode ser herdada (50\% dos casos) ou não (AZULAY, 2008). As manchas café au lait são geralmente as primeiras manifestações visíveis da NF-1 (WOLFF et al., 2011).

A NF-1 pode afetar uma pessoa de forma leve até mais gravemente, e normalmente as crianças e adolescentes são os mais afetados. As principais manifestações da NF-1 são: máculas café com leite, nódulos de Lisch, efélides inguinais e axilares, neurofibromas, neurofibromas plexiformes, glioma óptico, alterações ósseas, alterações endócrinas, alterações do sistema nervoso central e dificuldades de coordenação motora, de cognição, de aprendizagem escolar e de socialização (MARQUES et al., 2015).

\section{Neurofibromatoses}

Em 1882, o médico patologista alemão Friedrich Daniel Von Recklinghausen descreveu como Neurofibromatose a doença neuroectodérmica constituída de um conjunto de manifestações clínicas que comprometem principalmente a pele, sistema nervoso, olhos e ossos, com alterações mentais e endócrinas nos pacientes acometidos (SAMPAIO \& RIVITTI, 2007).

É uma doença autossômica dominante de elevada penetrância e expressividade variável. Aproximadamente metade dos casos tem relação com herança genética familiar, enquanto que a outra metade advém de mutações de novo, ou seja, mutações espontâneas que não foram herdadas dos pais (MARTINS et al., 2007).

Em relação à expressividade, é o "grau em que um determinado gene é expresso fenotipicamente. Forma pela qual um caráter hereditário se manifesta em determinado meio, pois um gene mutante pode expressar-se diversamente nas pessoas que o possuem, segundo a influência de fatores do meio interno ou externo" (REY, p. 355, 2003). Consequentemente, na neurofibromatose, a expressividade variável determina que os portadores possam ter diferentes manifestações clínicas, mesmo dentro de uma mesma família. Essa heterogeneidade característica da doença faz com que alguns pacientes possam ter características leves ou graves, 
e também um doente gravemente afetado possa ter descendentes levemente afetados e vice-versa (SAMPAIO \& RIVITTI, 2007).

Existem várias síndromes clínicas enquadradas no grupo das neurofibromatoses. Carey et al. (1986) propôs esta classificação das síndromes em 5 tipos: neurofibromatose tipo 1 (NF-1) clássica; NF-2 - acústica, NF-3 - segmentar, NF-4 - MCCL (manchas café com leite) familial e NF-5 - neurofibromatose com fenótipo Noonan, na qual os afetados possuem algumas características da neurofibromatose clássica (MCCL, neurofibromas, efélides intertriginosas, nódulos de Lisch) e algumas características da Síndrome de Noonan (pescoço curto, implantação baixa de cabelos na nuca, baixa estatura, cardiopatias, retardo mental, hipotonia, ptose palpebral, hipoplasiamalar, etc.) (SAMPAIO \& RIVITTI, 2007).

Os principais tipos de neurofibromatoses são a NF-1 e a NF-2. A NF-1 representa 90\% dos casos, acomete um em cada 3000 nascidos vivos, e o defeito cromossomial localiza-se no braço longo do cromossomo 17 locus 11.2. Já a NF-2 corresponde à neurofibromatose acústica bilateral - na qual ocorrem principalmente schwannomas vestibulares bilaterais -, acomete um a cada 40000 nascidos vivos e a alteração genética localiza-se no braço longo do cromossomo 22 locus 12 (AZULAY, 2008). A NF-1, portanto, é a mais prevalente entre as síndromes do grupo das neurofibromatoses, causando sinais e sintomas clínicos característicos, além de problemas no desenvolvimento social, motor e cognitivo; pode afetar uma pessoa desde formas mais leves até mais graves, sendo normalmente as crianças e adolescentes os mais afetados (MARQUES et al., 2015)

\section{Neurofibromatose Tipo 1}

\section{Epidemiologia e Genética da NF-1}

A neurofibromatose tipo 1 é uma das doenças genéticas mais frequentes, acometendo cerca de um a cada 3000 nascidos vivos no mundo (GELLER \& BONALUMI FILHO, 2001). É a síndrome mais frequente do grupo das neurofibromatoses, acometendo ambos os sexos igualmente e ocorrendo em todas as raças (AZULAY, 2008).

A NF-1 é herdada num padrão autossômico dominante, e seu gene apresenta $100 \%$ de penetrância. As mutações acometem o braço longo do cromossomo 17 locus 11.2. Trata-se de um gene muito grande - compreende $350 \mathrm{~kb}$ de DNA genômico -, por isso é susceptível a várias mutações diferentes (AZULAY, 2008). A doença apresenta uma taxa de mutação elevada, uma das mais altas das doenças genéticas; desse modo, não há correlação entre fenótipo e genótipo, exceto para indivíduos que apresentem deleções completas do gene NF-1. Nesse caso, estes indivíduos apresentam risco elevado para neurofibromas precoces, neurofibromas plexiformes, 
dismorfismo de órgãos e retardo mental. A doença é mais grave quando herdada da mãe do que quando herdada do pai (WOLFF et al., 2011).

O gene da NF-1, com seu tamanho significativo, contém 59 éxons e codifica um peptídeo de mais de 2800 aminoácidos. O produto protéico desse gene é denominado neurofibromina, e se encontra em quantidade abundante no tecido cerebral, incluindo neurônios, oligodendrócitos e células de Schwann não mielinizadas (WOLFF et al., 2011). A neurofibromina é o regulador negativo da RAS - uma proteína proto-ontogênica ligada à membrana celular -, através da sua ação inibitória na enzima farnesiltransferase. Por ser homóloga às proteínas ativadoras da função GTPase que aceleram a hidrólise da proteína p21 ras-GTP para p21 ras-GDP, a neurofibromina passa a RAS da forma ativa para a inativa. Na NF-1, com a mutação do gene, essa neurofibromina acaba sendo produzida com uma estrutura diferente da original, atuando de forma ineficiente e diminuindo a regulação negativa da RAS, resultando em não supressão da proliferação celular (XU, 1990).

Outro mecanismo que pode ocorrer na doença e explica a tumorigênese presente na NF-1 é a perda da heterozigosidade do gene, através da inativação do alelo normal em células somáticas (FRIEDMAN, 2014). A tumorigênese é iniciada quando ambas as cópias do gene param de funcionar normalmente, ou como resultado de uma mutação herdada, ou como resultado de um processo que interfere na função do alelo previamente normal (WOLFF et al., 2011). Mutações de perda de função heterozigótica são responsáveis pela doença, mas as variantes patogênicas podem ser diversas, incluindo mudanças nucleotídicas sem sentido, inserção ou deleção de bases nitrogenadas, mutações de splicing (em cerca de $30 \%$ dos casos), deleções de gene inteiro (em 4\%-5\% dos casos), mudanças no número de cópias intragênicas e outros rearranjos estruturais (FRIEDMAN, 2014).

\section{Características e Critérios Clínicos}

O diagnóstico de neurofibromatose tipo 1 deve ser suspeitado em indivíduos com qualquer um dos achados citados posteriormente e confirmado naqueles que atendem aos critérios diagnósticos para NF-1 desenvolvidos pelo National Institutes of Health (NIH) em 1988. Estes critérios do NIH para NF-1 são satisfeitos em um indivíduo que tem duas ou mais das seguintes características:

- seis ou mais máculas café au lait iguais ou maiores que $5 \mathrm{~mm}$ de diâmetro em indivíduos abaixo de 6 anos e maiores que 15 mm de diâmetro em indivíduos acima de 6 anos;

- dois ou mais neurofibromas de qualquer tipo;

- pelo menos um neurofibroma plexiforme;

- efélides nas regiões axilares e/ou inguinais; 
- um glioma do nervo óptico;

- dois ou mais nódulos de Lisch (hamartomas de íris);

- uma lesão óssea distinta, como displasia esfenoidal ou pseudartrose tibial;

- um parente de primeiro grau com NF-1 definido pelos critérios acima (FRIEDMAN, 2014).

As manchas café com leite são o sinal mais frequente da doença (MARTINS et al., 2007), aparecendo em mais de $90 \%$ dos casos. A segunda manifestação mais comum são as efélides, máculas pigmentadas que não se encontram em áreas expostas ao sol, mas observadas principalmente nas regiões inguinais e axilares. As efélides são encontradas em $90 \%$ das crianças e mais comum entre os 3 e 5 anos (MARQUES \& VERONEZ, 2015).

\section{Complicações da Neurofibromatose Tipo 1}

\section{Complicações Relacionadas à Infância e Adolescência}

Apesar da gravidade dos problemas causados pela doença, geralmente cerca de metade das pessoas com NF-1 leva uma vida normal e produtiva. Algumas pessoas com NF1 podem apresentar apenas manchas café com leite, poucos neurofibromas e serem muito pouco afetadas no desenvolvimento, mas outras podem ser gravemente afetadas em sua aparência e na realização de atividades físicas ou escolares (DE REZENDE et al., 2008).

As crianças com NF-1 são mais frequentemente afetadas por alterações como atraso de desenvolvimento puberal, dificuldades de linguagem e aprendizagem escolar, déficit de atenção e hiperatividade, alterações na percepção visuoespacial, dificuldades na motricidade fina dificuldade no planejamento e execução de tarefas. Porém, ainda não há um perfil neurocognitivo específico estabelecido para a doença, sabendo-se apenas que há envolvimento do sistema nervoso central e de funções corticais (MARTINS et al., 2007).

Os doentes não são afetados exatamente da mesma forma, mesmo pertencendo à mesma família; assim sendo, não é possível prever os problemas que a criança vai apresentar ao longo de sua vida. Alguns sinais da NF-1 podem ser visíveis no primeiro ano de vida, enquanto outros podem se desenvolver apenas com o passar do tempo; por exemplo, os neurofibromas geralmente se desenvolvem durante as mudanças hormonais que ocorrem na adolescência e durante a gravidez, ou com o uso de anticoncepcionais (DE REZENDE et al., 2008).

Crianças com NF-1 geralmente têm inteligência normal, mas aproximadamente $60 \%$ das crianças apresentam baixa atenção, hiperatividade ou alguma dificuldade na escola. As dificuldades na escola podem ser causadas também por alterações na percepção visuoespacial que a NF-1 pode gerar. Além disso, a maioria das pessoas com NF-1 (80\%) apresenta problemas na fala, o que favorece a dificuldade de aprendizagem e isolamento e exclusão sociais (DE REZENDE et al., 2008). 
Crianças e adolescentes com neurofibromatose tipo 1 estão sujeitas a desenvolverem quadros de déficit cognitivo, autismo, agressividade e transtorno de déficit de atenção e hiperatividade (TDAH). Alterações endócrinas como problemas de crescimento, puberdade precoce, hipogonadismo e feocromocitoma também foram identificados. Os indivíduos com NF1 também estão sujeitos a alterações de pressão arterial, principalmente hipertensão arterial sistêmica (MARQUES \& VERONEZ, 2015).

Existem diversos estudos enfatizando os impactos da NF-1 em crianças e adolescentes. Johnson et al. (1999) mostrou que, quando avaliados pelos pais, as crianças com NF-1 tinham significativamente mais problemas em comparação com os irmãos não afetados em tópicos como: problemas de socialização, problemas de atenção, ansiedade, depressão, problemas de pensamento, queixas somáticas e comportamento agressivo. Também notou-se uma dificuldade maior em relação àsatividades esportivas (MARQUES \& VERONEZ, 2015).

Em um estudo publicado por Hymanet al. (2005), 81\% das crianças com NF-1 tinham insuficiência moderada a grave em uma ou mais áreas do funcionamento cognitivo. Embora 51\% das crianças com NF-1 tivessem um desempenho fragilizado em tarefas de leitura, escrita e matemática, dificuldades de aprendizagem específicas estavam presentes em apenas $20 \%$ das crianças. Dificuldades de atenção estavam presentes em $63 \%$ das crianças com NF-1, sendo que $38 \%$ destas preenchiam os critérios de diagnóstico de transtorno de déficit de atenção e hiperatividade.

Pacientes com NF-1 que apresentam transtorno de déficit de atenção e hiperatividade, comparados com os portadores de NF-1 que não apresentam TDAH e com os pacientes que não apresentam nem NF-1 nem TDAH, possuem um QI (quociente intelectual) menor que os demais (HYMAN et al., 2005).

Em relação às alterações musculoesqueléticas, crianças e adolescentes com NF-1 também podem apresentar displasias esqueléticas e densidometria óssea diminuída, os quais podem predispor defeitos ósseos localizados. As alterações ósseas, como a pseudoartrose, ocorrem em cerca de 5\% das crianças com NF-1 e, em geral, são benignas, embora alguns pacientes sejam gravemente acometidos com arqueamento de ossos longos e até fraturas. A escoliose é a principal anormalidade esquelética nos pacientes com NF-1 em até $60 \%$ dos casos, sendo a maioria antes dos 15 anos de idade (DARRIGO JR et al., 2008).

$\mathrm{Na}$ idade pediátrica o glioma do nervo óptico é o tumor mais comum, ocorrendo em cerca de $15 \%$ dos casos. Geralmente surge até o oitavo ano de vida e caracteriza-se clinicamente por diminuição da acuidade visual, assimetria da face com proptose e estrabismo. Podem ocorrer concomitantemente com gliomas do tronco cerebral. A grande maioria é caracterizada 
histologicamente como astrocitomas pilocíticos benignos, envolvendo a via óptica numa extensão variável (MARTINS et al., 2007).

Num estudo clínico realizado por Martins et al. (2007), foram revistos os processos clínicos de 35 crianças (20 do sexo masculino, 15 do sexo feminino), com idade média de diagnóstico de 4 anos e 7 meses. O motivo mais frequente pelo qual as consultas eram marcadas era a presença de manchas cutâneas (35/35), sendo outros motivos os antecedentes familiares, neurofibroma cutâneo, pseudoartrose da tíbia, cefaleias, convulsões, má progressão estaturoponderal e dificuldades escolares. Os critérios de diagnóstico clínico apresentavam as seguintes frequências: manchas café au lait (35/35), antecedentes familiares (22/35), efélides axilares ou inguinais (9/35), neurofibromas (5/35), nódulos de Lisch (4/35), glioma óptico (3/35), displasia do esfenóide ou de ossos longos (3/35), neurofibroma plexiforme (2/35). Três casos (3/35) apresentavam baixa estatura e 11/35 macrocrânea. No estudo do encéfalo por ressonância magnética nuclear, foram identificadas áreas de hiperintensidade em T2 (UBOs - unidentified bright objects) em 12 casos.

Ainda como parte da pesquisa de Martins et al. (2007), a avaliação cognitiva e psicológica foi efetuada em 12 casos, e o QI médio foi de 87; o diagnóstico de déficit de atenção e/ou hiperatividade foi estabelecido em $40 \%$ (14/ 35) das crianças; em 48\% (17/35) dos casos foram identificadas dificuldades escolares, mas apenas nove beneficiavam de apoios educativos; foram encontrados dificuldades nas áreas visuoespacial (5/12), grafoperceptiva (5/12), leitura (4/35), linguagem (3/35), grafomotora (3/12) e aritmética (3/12).

\section{Dificuldades de Aprendizado e Ajustes Cognitivos}

Cognição é o "termo genérico que abrange as funções nervosas superiores como a memória, a linguagem, as habilidades visuoespaciais, etc. Processo pelo qual um indivíduo adquire conhecimentos; inclui todos os aspectos de perceber, pensar e relembrar" (REY, p. 186, 2003).O déficit cognitivo nada mais é que um desenvolvimento desses processos mentais de forma deficiente, apresentando limitações no seu funcionamento adaptativo em pelo menos duas das seguintes áreas: comunicação, autocuidado, vida doméstica, habilidades acadêmicas, cuidados com a saúde e segurança e autossuficiência que pode ser observado pelas pessoas que o cercam, sendo que isto tem que ocorrer no período de desenvolvimento até os 18 anos de idade (DE ARAÚJO, 1998).

Aproximadamente $80 \%$ das crianças com NF-1 apresentam algum tipo de déficit cognitivo, sendo os mais comuns déficits na atenção, linguagem, habilidades visuoespaciais e nas funções executivas como planejamento, organização e automonitoramento. Há também uma deficiência nas habilidades de alfabetização e aritmética por esses pacientes. Porém, mesmo com 
essas alterações, as crianças com NF-1 não apresentaram uma diminuição significativa dos níveis gerais de inteligência - que é a capacidade de compreensão e resolução de problemas comparados com a população e irmãos sem a doença, permanecendo dentro da faixa normal de funcionamento intelectual (LEWIS et al., 2016).

Hyman et al. (2005) avaliou a freqüência e a gravidade de déficits cognitivos específicos em crianças com neurofibromatose tipo 1 em uma grande coorte. Foram realizadas extensas avaliações cognitivas em 81 crianças com NF-1 e idades de 8 a 16 anos e seu desempenho foi comparado com o de 49 controles de irmãos não afetados. $81 \%$ das crianças com NF-1 apresentaram comprometimento moderado a grave em uma ou mais áreas do funcionamento cognitivo. Apesar de $51 \%$ das crianças com NF-1 terem realizado as tarefas de leitura, ortografia e matemática de forma deficiente, dificuldades específicas de aprendizagem (conforme definido pelas discrepâncias de desempenho do QI) estavam presentes em apenas $20 \%$ das crianças. Dificuldades de atenção sustentada estavam presentes em $63 \%$ das crianças com NF-1, com 38\% das crianças com NF-1 preenchendo os critérios diagnósticos para déficit de atenção e hiperatividade.

O perfil neuropsicológico da NF-1 é caracterizado por déficits nas habilidades perceptuais (visuoespacial e visuoperceptual), funcionamento executivo (planejamento e formação de conceitos abstratos) e atenção (sustentada e comutativa) (HYMAN et al., 2005). Curiosamente, a memória verbal e visual não foi afetada em crianças com NF-1 no estudo de Hyman et al. (2005), e suas habilidades de memória foram em geral mais fortes do que o seu nível de função intelectual geral. Embora as habilidades linguísticas expressivas e receptivas tenham sido significativamente prejudicadas em crianças com a doença, elas pareciam estar relativamente melhor preservadas do que as habilidades visoespaciais, uma vez que o QI é levado em conta.

Como conclusão da pesquisa de Hyman et al. (2005), houve uma frequiência extremamente alta de problemas cognitivos em crianças com neurofibromatose tipo 1, tornando a disfunção cognitiva a complicação mais comum para afetar a qualidade de vida nessas crianças.

Lehtonen et al. (2015) realizou um estudo com 49 crianças com NF-1 (25 meninos e 24 meninas, com idade média de 11 anos e 9 meses) que realizavam acompanhamento no The Manchester Regional Genetics Service do Saint Mary's Hospital na Inglaterra, objetivando investigar os principais déficits cognitivos em crianças com a doença. Foram também recrutados para este estudo 19 irmãos saudáveis de crianças com NF-1 (9 meninos e 10 meninas, com idade média de 12 anos e 7 meses). Os participantes completaram uma bateria de testes cognitivos, incluindo testes de inteligência, realização acadêmica, atenção, funcionamento visuoperceptual, aprendizagem visual, funcionamento executivo e testes não-verbais de memória de trabalho. As 
crianças com NF1 apresentaram QI em escala total significativamente menor e menor desempenho acadêmico do que seus irmãos. Ainda em comparação com seus irmãos, também tiveram um processamento visuo-espacial, aprendizado visual associado, memória de trabalho não verbal e função executiva significativamente piores.

Lewis et al. (2016), em seu estudo com 23 crianças portadoras de NF-1 e idades entre 6 e 14 anos (aproximadamente), recrutadas do The Children's Hospital em Westmead (Sydney, Australia), avaliou se a competência social dessas crianças teria alguma relação com a cognição de cada uma delas. A competência social foi avaliada através da ferramenta $S C P Q-P$ (questionário de competência social com os pares - formulário parental), um questionário de nove itens sobre qualidade e quantidade de amizades das crianças, popularidade percebida, natureza das relações com filhos da mesma idade e envolvimento em atividades sociais.

As relações entre competência social (investigadas pela ferramenta $S C P Q-P)$, FSIQ(Full Scale IQ - teste para avaliação do quociente intelectual) e as habilidades executivas diárias (BRIEF e Conners 3-PL, classificações de escala de funcionamento executivo) no grupo NF-1 foram investigadas por Lewis et al. (2016). Neste estudo, as classificações de $S C P Q-P$ não foram significativamente correlacionadas com $F S I Q$, e os índices $S C P Q-P$ não foram correlacionados significativamente com a classificação da função executiva nas subescalas e índices BRIEFou na escala de conteúdo do funcionamento executivo Conners 3-PL.

\section{Habilidades Sociais}

A origem do movimento das habilidades sociais é frequentemente atribuída a Salter (1949), considerado um dos pais da terapia comportamental, o qual promoveu técnicas para aumentar a expressividade verbal e facial descritas em seu livro Conditioned Reflex Therapy (BOLSONI-SILVA, 2002).

Caballo (2007) afirma que comportamento socialmente habilidoso baseia-se na expressão, pelo indivíduo, de atitudes, sentimentos, opiniões, desejos, respeitando a si próprio e aos outros, existindo, em geral, resolução dos problemas imediatos da situação e diminuição da probabilidade de problemas futuros. Entre os componentes da habilidade social, tem-se: falar em público, iniciar e manter conversações, expressar amor, agrado e afeto, defesa dos próprios direitos, enfrentar as críticas, desculpar-se ou admitir ignorância e expressar opiniões pessoais. Em geral, espera-se que a habilidade social produza mais efeitos positivos do que negativos e, clinicamente, é importante avaliar tanto o que a pessoa faz quanto o que o seu comportamento provoca nos demais.

No estudo realizado por Lewis et al. (2016) no The Children's Hospital em Westmead (Sydney, Australia), investigou-se a classificação de pais de 23 crianças com NF-1 e idades entre 
6 e 14 anos (aproximadamente) através de um questionário de competência social (the Social Competence with Peers Questionaire, Parent Form - SCPQ-P), no qual avaliou-se em 9 itens a qualidade e quantidade de amizade das crianças, a popularidade percebida dessas crianças, a natureza das relações com crianças da mesma idade e seu envolvimento em atividades sociais. Os resultados foram comparados com um grupo controle de 23 crianças da mesma faixa etária.

O $S C P Q-P$ foi desenvolvido para estimular a avaliação parental das dificuldades de competência social em crianças em idade escolar, com o objetivo de fornecer detalhes para intervenção direcionada a crianças com problemas sociais. Como tal, é bem adequado para a investigação da competência social em uma população clínica. Pontuações mais altas na escala (que vai de 0 a 2) indicam maior competência social (LEWIS et al., 2016).

No $S C P Q-P$, o grupo NF-1 apresentou escores de competência social significativamente menores em relação aos controles. Além disso, o teste de Levene para a igualdade de variâncias revelou uma variabilidade significativamente maior nas classificações de competência social total para as crianças NF-1 em comparação com o grupo controle (LEWIS et al., 2016).

As análises ao nível do item $S C P Q-P$ revelaram que as crianças NF-1 apresentaram classificações significativamente mais baixas nos seguintes itens em comparação com os controles: "tem pelo menos um amigo próximo", "tem amizades estáveis com outras crianças de sua idade", "é fácil fazer amigos", "tem boas relações com os colegas", “é popular entre outros a sua idade" e "vê um amigo ou amigos socialmente nos finais de semana". As classificações foram semelhantes entre os grupos NF-1 e controle nos seguintes itens: "outras crianças convidam-no para casa", "outras crianças convidam-no para eventos sociais ou atividades" e "é convidado para as festas" (LEWIS et al., 2016)

Os resultados do estudo de Lewis et al. (2016) indicaram que as crianças com NF-1 apresentaram uma competência social mais pobre do que os controles. Esses déficits de competência social não estavam relacionados com a sintomatologia do Transtorno de Déficit de Atenção com Hiperatividade, QI de Escala Integral ou comportamento executivo funcional. Entretanto, as dificuldades com a competência social estavam significativamente relacionadas com a sintomatologia do Transtorno do Espectro Autista (TEA) e comportamentos socialmente ansiosos/evitadores na coorte NF-1.

No mesmo estudo realizado por Lewis et al. (2016), foram investigadas as relações entre a competência social e a sintomatologia do transtorno de déficit de atenção e hiperatividade TDAH (classificações Conners 3-PL de inatenção e hiperatividade/impulsividade) e sintomatologia do TEA (classificação $S R S$ ) no grupo NF-1. Não foram identificadas associações significativas entre os sintomas de TDAH (desatenção, hiperatividade/impulsividade) e a classificação $S C P Q-P$ para os participantes da NF-1. Os índices $S C P Q-P$ foram 
significativamente e negativamente correlacionados com os níveis totais da sintomatologia autista (escore total do $S R S$ ) e também com as subescalas SRS de Comunicação Social, Motivação Social e Maneirismos Autistas.

Para determinar se os participantes do grupo NF-1 sem diagnóstico de TDAH ou TEA concomitante demonstraram dificuldades de competência social, as análises anteriores foram repetidas após a exclusão dos cinco participantes do grupo NF-1 com um diagnóstico psicológico comórbido (TDAH). Mesmo após a exclusão dos participantes com comorbidades psicológicas, o grupo NF-1 apresentou escores de competência social global significativamente mais baixos em comparação com os controles. Novamente, o teste de Levene para a igualdade de variâncias revelou uma variabilidade significativamente maior nas classificações de competência social total para as crianças NF-1 em comparação com o grupo controle (LEWIS et al., 2016).

Allen et al. (2016) realizou um estudo que examinou o funcionamento social e o reconhecimento da expressão facial (REF) em crianças com neurofibromatose tipo 1 em comparação com os pares de desenvolvimento típico. Especificamente, a pesquisa teve como objetivo identificar as relações entre a habilidade neurocognitiva, REF e funcionamento social. Crianças com idades entre 8 e 16 anos, com NF-1 $(n=23)$ e pares com desenvolvimento típico $(n=23)$ foram recrutadas durante visitas clínicas regularmente programadas e através de anúncios num site de ensaios clínicos institucionais, respectivamente. Os participantes completaram uma medida de REF, um teste de inteligência abreviado e questionários sobre sua qualidade de vida e funcionamento comportamental. Os pais também foram convidados a preencher questionários sobre o funcionamento sócio-emocional e cognitivo dos seus filhos.

Como esperado, Allen et al. (2016) encontrou diferenças significativas entre as crianças com NF-1 e os pares em desenvolvimento típico nos domínios de funcionamento social e REF. Dentro da amostra de crianças com NF-1, não houve associação significativa entre as medidas de cognição, funcionamento social e habilidades de reconhecimento facial. Como conclusão do estudo, Allen et al. (2016) afirmou que as crianças com NF-1 exibiram altas taxas de comprometimento social e habilidades REF fracas em comparação com os controles. A ausência de associações entre REF com variáveis cognitivas e sociais, entretanto, sugere algo único sobre essa habilidade social em crianças com NF1.

\section{Transtorno do Espectro Autista e Transtorno de Déficit de Atenção e Hiperatividade}

O Transtorno do Espectro Autista (TEA) é o mais importante transtorno do neurodesenvolvimento, no qual os sintomas costumam ser reconhecidos durante o segundo ano de vida. Em geral, o desenvolvimento anormal dos pacientes com autismo é percebido cedo, logo após o nascimento (ANDREASEN, 2009). Se os atrasos do desenvolvimento forem graves, 
podem ser vistos antes do primeiro ano de idade e, se sutis, podem ser vistos apenas após os dois anos. O transtorno do espectro autista não é um transtorno degenerativo, sendo comum que aprendizagem e compensação continuem ao longo da vida (DSM-5, 2014).

O comprometimento da interação social é um dos primeiros sinais do transtorno, e a dificuldade de desenvolvimento da linguagem é a primeira manifestação percebida pelos pais. $\mathrm{O}$ transtorno é vitalício e pode ser confundido com diagnósticos diferenciais como psicose infantil, surdez e retardo mental. A maioria dos autistas exibe algum traço de retardo mental, porém alguns podem ter inteligência normal e outros podem apresentar talentos e habilidades muito específicos, principalmente nas áreas da matemática e da música (ANDREASEN, 2009).

Os critérios para Autismo, segundo o Manual Diagnóstico e Estatístico de Transtornos mentais da American Psychiatric Association (DSM-5, 2014), são relacionados em A, B, C, D e E, e incluem: A - déficits persistentes na comunicação social e na interação social em múltiplos contextos, déficits nos comportamentos comunicativos não verbais usados para interação social e déficits para desenvolver, manter e compreender relacionamentos; B - padrões restritivos e repetitivos de comportamento, interesses ou atividades (movimentos motores, uso de objetos ou fala estereotipados ou repetitivos; insistência nas mesmas coisas;interesses fixos e altamente restritos que são anormais em intensidade ou foco; hiper ou hiporreatividade a estímulos sensoriais ou interesse incomum por aspectos sensoriais do ambiente); C - os sintomas devem estar presentes precocemente no período do desenvolvimento, porém podem não se tornar plenamente manifestos até que as demandas sociais excedam as capacidades limitadas ou podem ser mascarados por estratégias aprendidas mais tarde na vida; D - os sintomas causam prejuízo clinicamente significativo no funcionamento social, profissional ou em outras áreas importantes da vida do indivíduo no presente. E - essas perturbações não são mais bem explicadas por deficiência intelectual ou por atraso global do desenvolvimento.

O Transtorno de Déficit de Atenção e Hiperatividade (TDAH) é caracterizado por dois grupos amplos de sintomas: dificuldade para se concentrar e manter a atenção (1) e hiperatividade e impulsividade (2) (ANDREASEN, 2009). A desatenção manifesta-se no comportamento do paciente com TDAH como divagação em tarefas, falta de persistência e desorganização. A hiperatividade refere-se à atividade motora ou conversa excessivas quando não apropriado. A impulsividade refere-se a ações precipitadas que ocorrem no momento sem premeditação e com elevado potencial para dano à pessoa; também pode se manifestar com intromissão social e/ou tomada de decisões importantes sem considerações acerca das consequências em longo prazo (DSM-5, 2014).

O TDAH começa na infância e exige-se que até os 12 anos de idade o paciente já possua uma manifestação clínica característica da doença (DSM-5, 2014). É comum em crianças 
pequenas e em idade escolar, sendo mais prevalente em meninos do que em meninas, com uma proporção de 3:1 (ANDREASEN, 2009).

Atrasos leves no desenvolvimento linguístico, motor ou social não são específicos do TDAH, embora costumem ser comórbidos. As características associadas podem incluir baixa tolerância a frustração, irritabilidade ou transitoriedade do humor. Mesmo na ausência de um transtorno específico da aprendizagem, o desempenho acadêmico ou profissional costuma estar prejudicado (DSM-5, 2014). Aproximadamente 50\% das crianças com TDAH têm um bom prognóstico, porém o TDAH na infância persiste nos adultos jovens em até $70 \%$ dos casos (ANDREASEN, 2009).

O TDAH a desatenção fica mais proeminente e prejudicial durante o período do ensino fundamental. No período pré-escolar, a principal manifestação é a hiperatividade. Os sintomas de hiperatividade motora geralmente ficam menos claros na adolescência e na vida adulta, embora persistam dificuldades como planejamento, inquietude, desatenção e impulsividade. Já na adolescência, sinais de hiperatividade são menos comuns, podendo limitar-se a comportamento mais inquieto ou sensação interna de nervosismo ou impaciência (DSM-5, 2014).

Os critérios do TDAH, segundo o DSM-5 do American PsychiatricAssociation(2014) também são relacionados em A, B, C, D e E:

A. Padrão persistente de desatenção e/ou hiperatividade-impulsividade que interfere no funcionamento e no desenvolvimento, conforme caracterizado por (1) e/ou (2):

1. Desatenção: Seis (ou mais) dos seguintes sintomas persistem por pelo menos seis meses em um grau que é inconsistente com o nível do desenvolvimento e têm impacto negativo diretamente nas atividades acadêmicas e sociais: com frequência não presta atenção em detalhes ou comete erros por descuido em tarefas escolares, no trabalho ou durante outras atividades; tem dificuldade de manter a atenção em tarefas ou atividades recreativas; com frequência parece não escutar quando alguém lhe dirige a palavra diretamente; frequentemente não segue instruções até o fim e não consegue terminar trabalhos escolares, tarefas ou deveres no local de trabalho; frequentemente tem dificuldade para organizar tarefas e atividades; evita ou não gosta de se envolver em tarefas que exijam esforço mental prolongado, como lições de casa; frequentemente perde coisas necessárias para tarefas ou atividades; com frequência é facilmente distraído por estímulos externos; com frequência se esquece de atividades cotidianas.

2. Hiperatividade e impulsividade: Seis ou mais dos seguintes sintomas persistem por pelo menos seis meses em um grau que é inconsistente com o nível de desenvolvimento e tem impacto negativo diretamente nas atividades sociais e acadêmicas: frequentemente remexe ou batuca as mãos ou os pés ou se contorce na cadeira; frequentemente levanta da cadeira em situações em que se espera que permaneça sentado; frequentemente corre ou sobe nas coisas em 
situações em que isso é inapropriado; com frequência é incapaz de brincar ou se envolver em atividades de lazer calmamente; com frequência não consegue ficar parado sem fazer alguma coisa; frequentemente fala demais; frequentemente deixa escapar uma resposta antes que a pergunta tenha sido concluída; frequentemente tem dificuldade para esperar a sua vez; com frequência interrompe ou se intromete em conversas ou atividades.

B. Vários sintomas de desatenção ou hiperatividade-impulsividade estavam presentes antes dos 12 anos de idade.

C. Vários sintomas de desatenção ou hiperatividade-impulsividade estão presentes em dois ou mais ambientes.

D. Há evidências claras de que os sintomas interferem no funcionamento social, acadêmico ou profissional ou de que reduzem sua qualidade.

E. Os sintomas não ocorrem exclusivamente durante o curso de esquizofrenia ou outro transtorno psicótico e não são mais bem explicados por outro transtorno mental.

Walsh et al. (2013) realizou um estudo para avaliar a prevalência de sintomas do Transtorno do Espectro Autista (TEA) e do Transtorno de Déficit de Atenção e Hiperatividade (TDAH) e a relação entre eles, através da análise de 66 pacientes com idade média de 10 anos e 11 meses e com diagnóstico de NF-1 recrutados do Children's National Medical Center em Washington DC, nos Estados Unidos. Dois testes-base foram utilizados no estudo, o SRS (Social Responsiveness Scale) e o VADPRS (Vanderbilt ADHD Diagnostic Parent Rating Scale). O SRS é um instrumento de rastreio concebido para identificar deficiências sociais e para distinguir os sintomas de TEA de outras condições da infância, enquanto o VADPRS foi criado para ser uma ferramenta de rastreio para avaliar a presença de TDAH, transtorno desafiante de oposição, transtorno de conduta e ansiedade/depressão.

Walsh et al.(2013) concluiu em seu estudo que 40\% da amostra de NF-1 havia aumentado os níveis de sintomas atingindo significância clínica no $S R S$ e $14 \%$ atingiram níveis compatíveis com aqueles observados em crianças com TEA. Esses níveis elevados não foram explicados pela gravidade da doença NF-1 ou por transtornos comportamentais de externalização/internalização. Houve uma relação estatisticamente significativa entre os sintomas de TDAH e TEA. Particularmente salientes foram as relações entre déficits de atenção e hiperatividade, com prejuízos na consciência social e motivação social.

Em outro estudo organizado por Garg et al. (2013) foram analisados os questionários de TEA (Social Responsiveness Scale - SRS), TDAH (Conners' Parent Rating Scale-Revised $C P R S-R$ ) e outros dados de morbidade psiquiátrica (Strengths and Dificulties Questionnaire $S D Q)$ de pais e professores de 207 crianças com idade entre 4 e 16 anos no UK North West Regional Genetic Service, na Inglaterra.A taxa de resposta dos pais foi de 52,7\% (109/207 
crianças, com idade média de 9 anos e 11 meses). O SRS mostrou que em 29,4\% (32/109) das crianças, o autismo estava na faixa clínica grave e em 26,6\% (29/109) na faixa de leve a moderada. Os resultados do $C P R S-R$ mostraram que 53,8\% (57/106) das crianças estavam na faixa clínica do TDAH . Com base nas pontuações na escala de dificuldades totais do $S D Q$, $41,5 \%$ (44/106) das crianças encontravam-se na faixa normal e 14,2\% (15/106) estavam na faixa limítrofe. $25 \%(26 / 104)$ das crianças preencheram critérios tanto para o autismo clínico como para o TDAH.

Esta amostra populacional representativa de crianças com NF-1 avaliadas por Garg et al. (2013) indica uma alta prevalência de sintomas de TEA associados com NF-1, bem como coocorrência substancial com sintomas de TDAH. Os resultados esclarecer a psicopatologia de NF1 e mostram o distúrbio como uma causa potencialmente importante de um gene solitário para sintomas de autismo.

Numa segunda fase desse mesmo estudo (GARG et al., 2013) um total de 109 (52,7\%) dos 207 respondedores da fase de rastreio inicial foram agrupados utilizando a Escala de Responsabilidade Social (SRS) como TEA significativo, TEA moderado ou não-TEA. 23 casos do grupo TEA significativo, 16 de TEA moderada e 8 de não-TEA (total $n=47$, idade média 11 anos e 7 meses), convidados proporcionalmente por seleção aleatória, foram vistos para confirmação confirmatória detalhada. As avaliações de Entrevista Diagnóstica de AutismoRevisado, Escala Observacional Diagnóstica de Autismo-Genérico e QI verbal foram combinados usando como padrão o Programa Colaborativo de Excelência em Critérios de Autismo em uma categorização de TEA para cada caso (TEA, TEA amplo com características parciais, não-TEA). Utilizou-se uma análise ponderada pré-planejada para derivar estimativas de prevalência para toda a população.

Como resultado deste estudo, quatorze $(29,5 \%)$ das 47 crianças apresentaram TEA, 13 $(27,7 \%)$ TEA amplo e 20 (42,5\%) não-TEA. O grupo TEA/TEA amplo mostrou predomínio masculino (1,7: 1,0), mas não diferiu significativamente do grupo não-TEA em relação ao QI, idade, status socioeconômico, herança, gravidade física ou escolaridade. A estimativa de prevalência populacional é de $24,9 \%$ TEA e $20,8 \%$ TEA amplo, com um total de 45,7\% mostrando algum fenótipo de espectro TEA.Os achados indicam alta prevalência de TEA em NF-1, com implicações para a prática clínica e pesquisa adicional em NF-1 como um modelo de gene único para autismo (GARG et al., 2013).

\section{Influência na Capacidade Motora}

NF-1 é associada com anormalidades esqueléticas como baixa estatura, escoliose, e fratura de ossos longos. Crianças com NF-1 possuem anormalidades ósseas e musculares, 
evidenciadas por diminuição da densidade mineral óssea, diminuição da força óssea e baixa massa muscular, e todas essas alterações podem predispor a fraturas e escoliose. Estas crianças também têm um desempenho nas funções neuromotoras mais pobre se comparada à dos irmãos não afetados (JOHNSON et al., 2010).

Johnson et al. (2010), em seu estudo feito com 26 crianças com NF-1 entre 4 e 15 anos recrutadas da University of Utah NF1 Clinic, nos Estados Unidos, usou um teste denominado BOT-2 (The Bruininks Osertsky Test of Motor Proficiency - second edition) para avaliar a proficiência motora de cada uma delas e comparar com o grupo normativo de mesma variação de idade. O teste em questão é considerado um marcador confiável das habilidades motoras finas e grosseiras de crianças de 4 a 21 anos de idade, e consiste em 8 subtestes que medem a precisão motora fina, integração motora fina, destreza manual, coordenação de membros superiores, coordenação bilateral, equilíbrio, agilidade/velocidade e força; as pontuações dos subtestes são combinadas em pontuações dentro de 4 áreas motoras: controle manual fino (controle da musculatura distal das mãos no desempenho de habilidades motoras finas), coordenação manual (controle e coordenação dos braços e mãos), coordenação corporal (controle e coordenação da postura e equilíbrio) e força e agilidade (aspectos da aptidão física e desempenho das habilidades motoras grosseiras). Um score denominado "Composto Motor Total" foi gerado para representar a pontuação global das 4 áreas motoras.

Os resultados do estudo de Johnson et al. (2010) mostraram que o grupo de crianças com NF-1 tiveram scores significativamente mais baixos que a amostra de teste normativa no "Composto Motor Total". 19\% do grupo NF-1 tiveram pontuações na categoria média, 54\% pontuaram na categoria abaixo da média e $27 \%$ marcaram na categoria bem abaixo da média. $\mathrm{O}$ estudo resultou em pontuações significativamente baixas para precisão motora fina, integração motora fina, coordenação de membros superiores, coordenação bilateral, equilíbrio, agilidade/velocidade e força, não havendo uma diferença significativa nos scores da destreza manual. Os subtestes de equilíbrio e coordenação bilateral contribuiram com $35 \%$ na variação do “Composto Motor Total”. O grupo NF-1 também teve uma pontuação significativamente baixa nas habilidades motoras finas, sendo que a pontuação da área motora do controle manual fino influenciou em 61\% a variação do "Composto Motor Total"; como essas habilidades motoras finas (escrita, desenho, corte e digitação) são importantes para a vida acadêmica, suas limitações devem ser exploradas a fim de determinar se contribuem para as dificuldades acadêmicas vistas nas crianças com NF-1.

Em outro estudo elaborado por Krab et al. (2011) recrutou 70 crianças com NF-1 e idades entre 3 e 12 anos aproximadamente, as quais faziam parte de um grupo atendido pelo Sofia Children's Hospital em Rotterdam, Holanda. Os envolvidos participaram de 3 tarefas 
denominadas Beery VMI, Saccade Adaptation e Prism Adaptation. O teste Beery VMI avaliava a coordenação motora fina e a integração motora-visual das crianças, as quais tiveram que copiar até 30 formas geométricas com complexidade ascendente usando papel e caneta. No teste Saccade Adaptation, estas crianças foram dispostas em frente a telas de computador, onde foram instruídas a olhar para um ponto vermelho único que pulava da esquerda para a direira da tela, visando o controle do desempenho e plasticidade dos movimentos oculares sacádicos. Já no teste denominado Prism Adaptation, foi avaliado a performance e plasticidade da coordenação do movimento das mãos, onde os avaliados teriam que mover a caneta - posicionada na mão dominante direita - em direção a um alvo projetado em um tablet à frente de cada um deles.

$\mathrm{O}$ resultado deste estudo mostrou que as crianças com NF-1 tiveram pontuações menores no teste Beery VMI, realizando mais erros no desenho das cópias do que os controles. A habilidade de adaptar os movimentos oculares sacádicos no grupo NF-1 pareceu estar dentro da normalidade. $55 \%$ das crianças com NF-1 e $64 \%$ dos controles estavam hábeis a modificar as amplitudes dos seus movimentos oculares dentro de um paradigma adaptacional clássico. Em relação ao teste Prism Adaptation, parece estar levemente comprometido nas crianças com NF-1. Embora ambos os grupos tivessem mostrado uma mudança significativa no ângulo de movimento das mãos após o deslocamento do vidro do prisma (no teste Prism Adaptation), o grau médio de adaptação foi menor nas crianças com NF-1 (Krab et al., 2011).

Mais tarde, Champion et al. (2014) avaliou 46 crianças e adolescentes com idades entre 7 a 17 anos com o diagnóstico de NF-1, recrutadas do The Children's Hospital em Westmead, Austrália. As habilidades motoras das crianças foram avaliadas com a ferramenta BOT-2 também utilizada no estudo de Johnson et al. (2010). A marcha de cada uma delas também foi analisada, através de um sistema eletrônico denominado GAITRite, com o qual as crianças foram instruídas a caminhar em uma esteira em seus próprios ritmos, enquanto os seguintes parâmetros temporais da marcha iam sendo registrados e calculados: velocidade $(\mathrm{cm} / \mathrm{s})$, cadência (passos/min), tempo do passo (s), comprimento do passo $(\mathrm{cm})$, comprimento dos passos largos $(\mathrm{cm})$, base de suporte $(\mathrm{cm})$ e porcentagem de apoio simples e duplo no ciclo de marcha (\%GC). Também ocorreram análises da cognição, função intelectual e memória de curto prazo dos indivíduos envolvidos.

No estudo acima, as crianças com NF-1 demonstraram deficiências nas habilidades motoras grosseiras quando comparadas com os dados normativos correspondentes à idade, com 28/39 exibindo equilíbrio e coordenação de membro superior prejudicados e 16/38 mostrando velocidade de execução e agilidade prejudicadas (CHAMPION et al., 2014).

As alterações de marcha relacionadas com a idade foram semelhantes às descritas em crianças com desenvolvimento normal, com velocidade crescente, tempo de passo, comrpimento 
do passo e comprimento dos passos largos com cadência decrescente. Entretanto, foram observadas variáveis espaçotemporais de marcha que apresentaram variações significativas daquelas relatadas em crianças com desenvolvimento típico. As crianças com NF-1 demonstraram reduções estatisticamente significativas na velocidade, cadência, comprimento dos passos largos e suporte único (GC\%), e um aumento do duplo suporte (GC\%) e tempo de passo. Mas os parâmetros de suporte duplo e único (GC\%) estavam dentro dos valores de referência normativos (CHAMPION et al., 2014).

Tais mudanças são consistentes com uma estratégia de caminhada cautelosa para preservar o equilíbrio à custa da velocidade. Um achado inesperado, no entanto, foi a tendência para uma base estreitada de suporte (largura da marcha), que requer maior estabilidade no plano frontal e não é tipicamente uma compensação para o equilíbrio prejudicado. No entanto, a base de suporte é uma medida que deve ser tratada com cautela, pois demonstrou ter menor repetibilidade do que outras medidas espaçotemporais (CHAMPION et al., 2014).

Correlações moderadas a grandes foram identificadas entre um número de habilidades cognitivas e motoras. A velocidade de corrida ea agilidade apresentaram as maiores associações com as variáveis neurocognitivas, incluindo o escore de estratégia da tarefa de memória de trabalho espacial, o índice de memória de trabalho e o índice de raciocínio perceptivo. Houve também associações significativas entre equilíbrio e índice de raciocínio perceptivo e índice de memória de trabalho. Em conjunto, essas associações sugerem que as crianças com NF-1 e deficiências neurocognitivas - particularmente memória de trabalho e déficits de raciocínio nãoverbal - são mais propensas a experimentar habilidades motoras reduzidas. Relações entre a memória de trabalho e habilidades motoras têm sido relatadas em crianças com transtorno de coordenação do desenvolvimento, levantando a possibilidade de processos anormais de neurodesenvolvimento compartilhados com processos subjacentes a estas habilidades em crianças com NF-1 (CHAMPION et al, 2014).

Foram identificadas associações significativas entre as variáveis neurocognitivas e a base de suporte e medidas de passo e de marcha. Há uma série de possíveis explicações para a associação entre a marcha e as variáveis neurocognitivas; uma sugere a possibilidade de disfunção cerebelar, uma estrutura cerebral mostrou ser importante na coordenação motora, equilíbrio e cognição, particularmente funções executivas. Entretanto, a tendência observada de crianças com NF-1 de ter uma base de suporte mais estreita é inconsistente com um mecanismo cerebelar prejudicado. Uma hipótese alternativa poderia ser que as anormalidades dentro da rede/circuito corticoestriatal, um circuito que liga intimamente regiões do córtex frontal às estruturas estriadas através do tálamo e globo pálido, contribui para a associação entre deficiências executivas e motoras. Embora esteja bem estabelecido que as funções executivas, 
como a memória de trabalho, são mediadas por circuitos corticoestriatais, dados recentes dos modelos de camundongos NF-1 estabeleceram um mecanismo de conexão entre a expressão do gene NF-1 e diminuição dos níveis de dopamina no corpo estriado, fortalecendo esta hipótese (CHAMPION et al., 2014).

\section{Tratamento e Suporte da NF-1 em Crianças e Adolescentes: o que Enfatizar}

A conduta inicial de avaliação a ser seguida deve sempre incluir história do paciente e dos familiares, com atenção especial para a presença de características de NF-1; exame clínico com destaque para pele, esqueleto e sistema neurológico; avaliação oftalmológica com exame de lâmpada de fenda; avaliação do desenvolvimento neuromotor em crianças. Os pacientes com complicações envolvendo os olhos, sistema nervoso central ou periférico, coluna e ossos longos devem ser encaminhados aos especialistas correspondentes (GELLER \& BONALUMI FILHO, 2001).

O acompanhamento de crianças e adolescentes com NF-1 deverá ser contínuo e considerar as múltiplas manifestações clínicas da doença (MARTINS et al., 2007). As pessoas com NF-1 vão precisar de exames médicos regulares e consultas anuais para verificar o estado geral de saúde e acompanhar o crescimento dos tumores, a pressão arterial, a visão e audição, o estado da coluna e avaliar se surgiram novos problemas. Em crianças pequenas, deve ser dada uma atenção especial ao crescimento, audição, visão, desenvolvimento, ossos e coluna. Em todas as crianças com menores de 10 anos, deve ser feito anualmente um exame oftalmológico em busca de sinais de glioma óptico (WOLFF et al., 2011). Em crianças maiores ou adolescentes, os neurofibromas plexiformes precisam ser verificados cuidadosamente. Radiografias e exames de ressonância magnética do cérebro, olhos e coluna podem ser necessários no acompanhamento (DE REZENDE et al., 2008).

Por ela se apresentar, geralmente, desde a infância, a NF-1 é uma potente causadora de desordens fisiológicas nesse período da vida do indivíduo. Por ser uma doença que desencadeia diversos tipos de alterações clínicas - resultado do acometimento de diversos locais diferentes do corpo - ela acarreta muitas dúvidas em relação ao diagnóstico dessas alterações e necessita de um olhar cauteloso sobre crianças e adolescentes que apresentam a doença, pois cada indivíduo terá uma clínica diferente, onde alguns terão um maior acometimento de um sistema e outros de outros sistemas corporais. Além disso, dentro de cada sistema acometido, existem diversos tipos de manifestações, e cada paciente terá uma manifestação mais prevalente e outra menos prevalente (DE REZENDE et al., 2008).

20 a $40 \%$ das crianças e adolescentes com NF-1 necessitam de serviços especiais de educação (GELLER \& BONALUMI FILHO, 2001). Os pais devem conversar com os 
professores se a criança está apresentando algum problema na escola, para que se avalie a necessidade de uma atenção especial (DE REZENDE et al., 2008). A abordagem da NF-1 deve incluir o envolvimento social e suporte familiar. A família necessita de uma boa orientação sobre esta doença genética, adquirindo certo conhecimento sobre os aspectos somáticos específicos esperados. As crianças com NF-1 e desenvolvimento de múltiplos problemas podem ter competência limitada nas habilidades esperadas para a idade (GELLER \& BONALUMI FILHO, 2001).

Para melhorar a integração do paciente no meio sociofamiliar, é importante considerar a psicoterapia como parte do tratamento, a qual costuma restaurar e construir o equilíbrio emocional desses pacientes. $\mathrm{O}$ apoio de educadores especializados facilita o trabalho dos pais em contornar problemas como a baixa autoestima e dificuldades em aprendizado de seus filhos. Um acompanhamento educacional e psicológico, portanto, é valoroso (GELLER \& BONALUMI FILHO, 2001).

Em relação às lesões, que comprometem a função e/ou estética, existem várias alternativas de controle que geralmente lançam mão de técnicas cirúrgicas, tais como cirurgia ortopédica para correção de pseudo-artrose e escoliose; cirurgia plástica na remoção de tumores, principalmente, em áreas de atrito e dos tumores que causam alguma alteração funcional do paciente; neurocirurgia para prevenir sérias complicações decorridas do desenvolvimento de tumores cerebral e espinhal. O laser de gás carbônico está sendo utilizado para a remoção de neurofibromas presentes em grande número, porém não se têm referências sobre a sua eficácia a longo prazo. A cirurgia a laser, para remoção de neurofibromas, pode ser menos dolorosa do que a cirurgia convencional. Para as lesões cosméticas, o pediatra ou o clínico deverá avaliar os benefícios subjetivos desta cirurgia em comparação com a morbidade e o potencial de recidiva dos tumores. Na remoção de manchas café com leite se tem utilizado o laser, mas nesta circunstância é um procedimento doloroso e que pode ter como sequela uma cicatriz. Porém, existem cosméticos muito úteis para a camuflagem das mesmas (GELLER \& BONALUMI FILHO, 2001).

Atualmente não existe cura para a NF-1, porém existem medidas paliativas que melhoram bastante as perspectivas de vida útil dos indivíduos afetados pelo distúrbio. Estas medidas estão essencialmente dirigidas para os diversos tipos de lesões que caracterizam a doença, além de outras que são direcionadas aos eventuais distúrbios de aprendizagem ou ao combate da estigmatização social. As alternativas extracirúrgicas são limitadas até o momento. Novos tratamentos estão em fase de avaliação e poderão representar novas opções de futuros tratamentos; eles estão direcionados aos mecanismos fisiológicos e a patogênese do desenvolvimento dos neurofibromas (GELLER \& BONALUMI FILHO, 2001). 
O médico deve ajudá-lo a ajustar a sua vida em relação à sua nova condição, através também de amplos esclarecimentos sobre a patologia. Depois de realizada a avaliação clínica, os tratamentos paliativos a serem instituídos devem considerar a presença de eventuais complicações. É de fundamental importância um bom relacionamento médico-paciente e um atendimento eficiente, em que o médico deve utilizar um linguajar acessível, claro e objetivo (GELLER \& BONALUMI FILHO, 2001).

\section{Considerações Finais}

A neurofibromatose tipo 1 tem sido observada em diversas partes do mundo, em todas as raças e possui correlação equivalente entre homens e mulheres (BONALUMI FILHO et al., 2010).Mesmo sendo uma doença de prevalência significativa - onde cada médico se deparará com 1 ou 2 casos alguma vez na vida -, é pouco conhecida pelos profissionais da medicina e escassa em informações sobre seus efeitos na vida do doente. Para se ter uma ideia da sua importância, a NF-1 é menos comum do que a Síndrome de Down (uma para 660 nascimentos), mas é mais frequente do que diabetes tipo I (uma para 13 mil) e diversas outras doenças somadas - fibrose cística, distrofia muscular de Duchenne, Doença de Huntington e Doença de Tay-Sachs (DE REZENDE et al., 2008).

Devido ao leque de consequências e clínicas que a doença possibilita, a NF-1 muitas vezes é subdiagnosticada em crianças e adolescentes, fazendo com que, sem um acompanhamento adequado, esses pacientes possam apresentar uma regressão no seu desenvolvimento e uma piora na sua qualidade de vida. Por isso, estudos mostram que é preciso fazer um acompanhamento anual da criança e do adolescente, usando-se parâmetros como: progresso escolar, alterações visuais, perímetro cefálico, altura, peso, pressão arterial e alterações no exame cardiovascular, além da avaliação da pele, da coluna vertebral e do desenvolvimento puberal (MARQUES \& VERONEZ, 2015).

Como a maioria dos sinais já está presente nos primeiros anos de vida, deve-se fazer um acompanhamento pediátrico contínuo para evitar maiores complicações no desenvolvimento dessas crianças e adolescentes, sempre atentando ao desenvolvimento escolar e social do paciente, acompanhando seu desenvolvimento motor, linguístico e cognitivo. A monitoração cardiovascular, dermatológica, neurológica e musculoesquelética passa a ser de extrema importância (MARTINS et al., 2007).

É muito importante que se faça uma anamnese e exame físico completos no paciente com suspeita de NF1, além de exames complementares. O objetivo é sempre evitar a malignização dos sintomas, em especial no período anterior à puberdade, fase onde os hormônios estão em 
maior atividade e podem exacerbar as complicações que não foram tratadas ou prevenidas (MARQUES et al., 2015).

Não existem relatos de cura para a doença, portanto as complicações podem surgir ao longo dos anos no paciente. Com isso, deve-se investir em ações de prevenção contra as possíveis complicações futuras e de suporte para as complicações já existentes. Por ser uma síndrome genética crônica, o acompanhamento contínuo dos sinais e sintomas e o auxílio psicossocial devem ser priorizados para um melhor desenvolvimento individual e social do paciente, melhorando cada vez mais sua qualidade de vida e diminuindo suas comorbidades e dificuldades diárias (MARQUES et al., 2015).

A NF-1 representa um dos distúrbios genéticos mais importantes no contexto de supervisão de saúde e orientação antecipatória de distúrbios nitidamente da faixa etária pediátrica. Compete então aos pediatras, o seguimento cuidadoso destas crianças, assegurando a necessidade de estar bem informado a respeito de todos os aspectos preventivos mais relevantes e pertinentes a este distúrbio (GELLER \& BONALUMI FILHO, 2001).

\section{Referências}

ALLEN, T.; WILLARD, V. W.; ANDERSON, L. M.; HARDY, K. K.; BONNER, M. J. Social functioning and facial expressions recognition in children with neurofibromatosis type 1. Journal of Intellectual Disability Research, v. 60, p. 282-293, 2016.

AMERICAN PSYCHIATRIC ASSOCIATION. Manual Diagnóstico e Estatístico de Transtornos Mentais DSM-5. 5. ed. Tradução: Maria Inês Corrêa Nascimento et al. Porto Alegre: Artmed, 2014.

ANDREASEN, N. C.; BLACK, D. W. Introdução à psiquiatria. 4. ed. Porto Alegre: Artmed, 2009.

AZULAY, R. D. Dermatologia. 5. ed., rev. e atual. Rio de Janeiro: Guanabara Koogan, 2008.

BALCER, L. J.; LIU, G. T.; HELLER, G.; BILANIUK, L.; VOLPE, N. J.; GALETTA, S. L.; MOLLOY, P. T.; PHILLIPS, P. C.; JANSS, A. J.; VAUGHN, S. MAGUIRE, M. G. Visual loss in children with neurofibromatosis type 1 and optic pathway gliomas: Relation to tumor location by magnetic resonance imaging. American Journal of Ophthalmology, v. 131, p. 442-445, 2001.

BARTON, B.; NORTH, K. Social skills of children with neurofibromatosis type 1. Developmental Medicine \& Child Neurology, v. 46, p. 553-563, 2004.

CABALlO, V. E. Manual de Técnicas de Terapia e Modificação do Comportamento. 2. ed. São Paulo: Santos Editora, 2007.

CERELLO, A. C.; GIANORDOLI-NASCIMENTO, I. F.; DE SOUZA, J. F.; RODRIGUES, L. O. C.; DE REZENDE, N. A. O QUE SÃO AS NEUROFIBROMATOSES? NF Tipo 1. Belo Horizonte: Centro de Referência em Neurofibromatoses, 2008.

CHAMPION, J. A.; ROSE, K. J.; PAYNE, J. M.; BURNS, J.; NORTH, K. N. Relationship between cognitive dysfunction, gait, and motor impairment in children and adolescents with neurofibromatosis type 1. Developmental Medicine \& Child Neurology, v. 56, p. 468-474, 2014.

DALLA VIA, P.; OPOCHER, E.; PINELLO, M. L.; CALDERONE, M.; VISCARDI, E.; CLEMENTI, M.; BATTISTELLA, P. A.; LAVERDA, A. M.; DA DALT, L.; PERILONGO, G. Visual outcome of a cohort of children with neurofibromatosis type 1 and optic pathway glioma followed by a pediatric neuro-oncology program. Neuro-Oncology, v. 9, p. 430-437, 2007. 
DARRIGO JUNIOR, L. G.; BONALUMI FILHO, A.; D’ALESSANDRO, D. S. M.; GELLER, M. Neurofibromatose tipo 1 na infância: revisão dos aspectos clínicos. Rev. Paul. Pediatria, v. 26, p. 176-182, 2008.

DARRIGO JUNIOR, L. G. Prevalence of plexiform neurofibroma in children and adolescents with type I neurofibromatosis. Journal of Pediatry, v. 83, p. 571-573, 2007.

DE ARAÚJO, U. F. O déficit cognitivo e a realidade brasileira. In: Diferenças e preconceito na escola: alternativas teóricas e práticas / Coordenação de Julio Groppa Aquino. São Paulo: Summus, 1998.

FRIEDMAN, J. M. Epidemiology of neurofibromatosis type 1. Journal of Medicine Genetics, v. 89, p. 1-6, 1999.

FRIEDMAN, J. M. Neurofibromatosis 1. Gene Reviews, 2014.

GARG, S.; LEHTONEN, A.; HUSON, S. M.; EMSLEY, R.; TRUMP, D.; EVANS, D. G.; GREEN, J. Autism and other psychiatric comorbidity in neurofibromatosis type 1: evidence from a population-based study. Developmental Medicine \& Child Neurology, v. 55, p. 139$145,2013$.

GARG, S.; LEHTONEN, A.; HUSON, S. M.; EMSLEY, R.; TRUMP, D.; EVANS, D. G.; GREEN, J. Neurofibromatosis Type 1 and Autism Spectrum Disorder. Pediatrics, v. 132, p. e1642-e1648, 2013.

GELLER, M.; BONALUMI FILHO, A. Neurofibromatose. In: CARAKUSHANSKY, G. Doenças Genéticas em Pediatria. 10. ed. Rio de Janeiro: Guanabara Koogan, 2001.

GRAF, A.; LANDOLT, M. A.; MORI, A. C.; BOLTSHAUSER, E. Quality of life and psychological adjustment in children and adolescents with neurofibromatosis type 1 . The Journal of Pediatrics, v. 149, p. 348-353, 2006.

HABIF, T. P. Dermatologia clínica: guia colorido para diagnóstico e tratamento. 4. ed. Porto Alegre: Artmed, 2005.

HOFMAN, K. J.; HARRIS, E. L.; BRYAN, N.; DENCKLA, M. B. Neurofibromatosis type 1: the cognitive phenotype. The Journal of Pediatrics, v. 124, p. 1-8, 1994.

HYMAN, S.L.; SHORES, A.; NORTH, K.N. The nature and frequency of cognitive deficits in children with neurofibromatosis type 1. Neurology, v. 65, p. 1037-1044, 2005.

JAMES, W. D. Café au Lait Spots. Medscape, 2016.

JOHNSON, B.; MACWILLIAMS, B.; CAREY, J. C.; VISKOCHIL, D. H.; D’ASTOUS, J. L.; STEVENSON, D. A. Motor Proficiency in Children with Neurofibromatosis Type 1. Pediatr Phys Ter, v. 22, p. 344-348, 2010.

JOHNSON, N. S.; SAAL, H. M.; LOVELL, A. M.; SCHORRY, E. K. Social and emotional problems in children with neurofibromatosis type 1: evidence and proposed interventions. The Journal of Pediatrics, v. 134, p. 767-772, 1999.

KRAB, L. C.; DE GOEDE-BOLDER, A.; AARSEN, F. K.; MOLL, H. A.; DE ZEEUW, C. I.; ELGERSMA, Y.; VAN DER GEEST, J. N. Motor Learning in Children with Neurofibromatosis Type I. The Cerebellum, v. 10, p. 14-21, 2011.

LEHTONEN, A.; GARG, S.; ROBERTS, S. A.; TRUMP, D.; EVANS, D. G.; GREEN, J.; HUSON, S. M. Cognition in children with neurofibromatosis type 1: data from a populationbased study. Developmental Medicine \& Child Neurology, v. 57, p. 645-651, 2015.

LEWIS, A. K.; PORTER, M. A.; WILlIAMS, T. A.; NORTH, K. N.; PAYNE, J. M. Social Competence in Children with Neurofibromatosis Type 1: Relationships with Psychopathology and Cognitive Ability. Journal of Childhood and Developmental Disorders, v. 2, n. 2, p. 1-12, 2016.

LISTERNICK, R.; CHARROW, J.; GREENWALD, M. J.; ESTERLY, N. B. Optic gliomas in children with neurofibromatosis type 1. The Journal of Pediatrics, v. 114, p. 788-792, 1989.

MARQUES, M.S.; VERONEZ, D.A. Demystifying neurofibromatosis type 1 in childhood: review article. Rev. Med. UFPR, v. 02, p. 79-84, 2015. 
MARTINS, C. L.; MONTEIRO, J. P.; FARIAS, A.; FERNANDES, R.; FONSECA, M. J. Neurofibromatose tipo 1 em idade pediátrica: o que vigiar?. Acta Med Port, v. 20, p. 393-400, 2007.

MAUTNER, V. F.; KLUWE, L.; THAKKER, S. D.; LEARK, R. A. Treatmentof AHDH in neurofibromatosistype 1. Developmental Medicine \& Child Neurology, v. 03, p. 164-170, 2002.

MUNIZ, M. P.; FERRAZ FILHO, J. R. L.; SOUZA, A. S.; ZANUSSO, S. H.; BERTELLI, E. C. P.; BERTOLLO, E. M. G. Neurofibromatose tipo 1: aspectos clínicos e radiológicos. Rev. Imagem, v. 28, p. 87-96, 2006.

NUNLEY, K. S.; GAO, F.; ALBERS, A. C.; BAYLISS, S. J.; GUTMANN, D. H. Predictive Value of Café au Lait Macules at Initial Consultation in the Diagnosis of Neurofibromatosis Type 1. Arch Dermatol., v. 145, p. 883-887, 2009.

REY, L. DICIONÁRIO DE TERMOS TÉCNICOS DE MEDICINA E SAÚDE. 2. ed. Rio de Janeiro: Guanabara Koogan S. A., 2003.

SAMPAIO, S. A. P.; RIVITTI, E. A. Dermatologia. 3. ed. rev. e ampl. São Paulo: Artes Médicas, 2008.

SINGHAL, S.; BIRCH, J. M.; KERR, B.; LASHFORD, L.; EVANS, D. G. R. Neurofibromatosis type 1 and sporadic optic gliomas. Arch Dis Child, v. 87, p. 65-70, 2002.

STEVENSON, D. A.; MOYER-MILEUR, L. J.; MURRAY, M.; SLATER, H.; SHENG, X.; CAREY, J. C.; DUBE, B.; VISKOCHIL, D. H. Bone mineral density in children and adolescents with neurofibromatosis type 1. The Journal of Pediatrics, v. 150, p. 83-88, 2007.

VUCINIC, D. Visual evoked potentials in children and adolescence with neurofibromatosis type 1. Clinical Neurophysiology, v. 126, p. 177, 2015.

WALSH, K. S.; VÉLEZ, J. I.; KARDEL, P. G.; IMAS, D. M.; MUENKE, M.; PACKER, R. J.; CASTELLANOS, F. X.; ACOSTA, M. T. Symptomatology of autism spectrum disorder in a population with neurofibromatosis type 1. Developmental Medicine \& Child Neurology, v. 55, p. 131-138, 2013.

WOLFF, K.; GOLDSMITH, L. A.; KATZ, S. I.; GILCHREST, B. A.; PALLER, A. S.; LEFFELL, D. J. Fitzpatrick - Tratado de Dermatologia. 7. ed. v. 2. Rio de Janeiro: Livraria e Editora Revinter Ltda, 2011.

XU, G.; O’CONNELL, P.; VISKOCHILL, D.; CAWTHON, R.; ROBERTSON, M.; CULVER, M.; DUNN, D.; STEVENS, J.; GESTELAND, R.; WHITE, R.; WEISS, R. The neurofibromatosis type 1 gene encodes a protein related to GAP. Cell Press, v. 62, p. 599-608, 1990. 